\title{
Improved Method of Fatigue Life Assessment for TiAl Alloys
}

\author{
R. C. Feng, ${ }^{a, b, 1}$ Z. Y. Rui, ${ }^{a, b, 2}$ G. T. Zhang, ${ }^{a, b, 3}$ C. F. Yan, ${ }^{a, b, 4}$ and X. B. Yi ${ }^{a, b, 5}$
}

a Key Laboratory of Digital Manufacturing Technology and Application, Ministry of Education, Lanzhou University of Technology, Lanzhou, China

${ }^{\mathrm{b}}$ School of Mechanical and Electronical Engineering, Lanzhou University of Technology, Lanzhou, China

1 frcly@163.com

2 zhiy_rui@163.com

3 zhangguotao_good@126.com

4 changf_yan@163.com

5 yibin2003@126.com

УДК 539.4

\section{Усовершенствованный метод оценки усталостной долговечности TiAl сплавов}

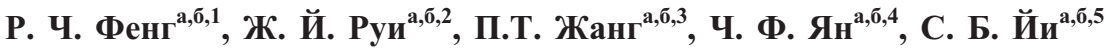 \\ а Лаборатория производства и применения цифровых технологий, Министерство образования, \\ Ланьчжоуский технологический университет, Ланьчжоу, Китай \\ ${ }^{\sigma}$ Факультет машиностроения и электроники, Ланьчжоуский технологический университет, \\ Ланьчжоу, Китай
}

Предложен новый метод оценки усталостной долговечности TiAl сплавов по результатам количественного и качественного анализа. С помощью количественного анализа определено влияние микроструктуры TiAl сплавов на их усталостную долговечность. Расчет усилия между дислокациями проведен по стандартной формуле, с помощью которой можно получить точный результат. Количественный и качественный анализ показал, что усталостную долговечность можно повысить путем введения микроэлементов, которые способствуют измельчению зерен.

Ключевые слова: титановый сплав алюминия, усталостная трещина, усталостная долговечность, оценка долговечности, усовершенствованный метод.

Introduction. The aero-gas turbine industry has been instrumental in the development of conventional titanium alloys and associated processing techniques since their beginning in the late 1950s [1]. Titanium aluminum alloys are known to be the key raw materials for manufacturing of the mechanical parts in high-temperature, and they have been widely used in many key areas, such as jet engine, aerogas turbine shell or structure, etc. Titanium aluminum alloys are examples of novel materials with great potential and competitiveness [2-4]. The reason why titanium aluminum alloys have been widely used is that they have several excellent characteristics such as low density, high stiffness, high resistance to burning, high strength at high temperatures, low coefficient of linear dilatation and high heat conductivity. 
Some trace elements (microelements) such as vanadium and yttrium are ususlly added to such allays, in order to improve their mechanical properties. Previous studies revealed that the high-oxidation resistance and mechanical properties of TiAl alloys can be effectively improved by the addition of trace alloying element $[5,6]$, while the ductility of TiAl alloys can be increased by the addition of vanadium [7, 8]. Most of the available articles are focused only on the performance improvement of TiAl alloys. However, the mechanical properties/performance and service life are inseparable. Taking this into account, an improved method of fatigue life assessment based on crack initiation for TiAl alloys is proposed in this study.

Fracture of metals starts from the crystal defects, such as dislocations and vacancies. These defects will develop into microcracks, and may gradually turn into macrocracks or cavities. Therefore, the fatigue crack evolution is conventionaslly subdivided into two segments: crack initiation and crack propagation. Respectively, the total fatigue life $\left(N_{f}\right)$ also includes two parts: crack initiation life $\left(N_{i}\right)$ and crack propagation life $\left(N_{p}\right)$. The relationship between $N_{i}$ and $N_{p}$ can be expressed as follows:

$$
N_{f}=N_{i}+N_{p}
$$

where crack initiation life $\left(N_{i}\right)$ includes crack nucleation life and microcrack propagation life. The process of fatigue life ranges from crack initiation to crack propagation and it could also be called the evolution of life in metallic materials.

The fatigue life is affected by numerous factors, such as stress, temperature, humidity, microstructure, et al. Authors [9] proved that dislocations and debris have great influence on the properties of TiAl alloys and the crack formation mechanism in these. Nevertheless, there is scarce information on the assessment of the crack initiation life of TiAl alloys. Yet there are fewer articles illustrating the relationship between the interaction forces of dislocations and fatigue life. Therefore, in this work, the emphpasis is made on the fatigue life assessment method which is based on the analysis of the relations linking between the interaction force of dislocations and fatigue life of materials at the room temperature.

Study [10] has provided modeling of fatigue and revealed some limits for the fatigue life. However, this work failed to yield the relationship between fatigue life and the factors which have influence on fatigue life of materials. In this paper, a detailed illustration will be carried out from the standpoint of mechanics.

1. Fatigue Crack and Assessment of Crack Initiation Life. The microcrack nucleation and propagation are important stages in the evolution of life in metallic materials, and they account for a significant portion in the total life of materials (the portion can be up to $90 \%$ in the high-cycle fatigue). Because of the difficulty of detecting defects at the microstructural level and the lack of quantitative information on crack nucleation and propagation for microcracks, the proposed method of crack initiation life assessment will be described using some available empirical formulas.

1.1. Fatigue Crack Nucleation Mechanism. In terms of crystal materials, the concept that is widely accepted is that crack nucleation is the result of partially obstructed plastic deformation. The local plastic deformation is a pre-requisite for crack formation, and the alternating stress is the key factor in the formation of fatigue cracks [12]. To illustrate the above viewpoint, several kinds of mechanisms have been put forward, such as the dislocation pile-up mechanism and the dislocation reaction mechanism. The process of microcrack shaped from dislocation pile-up can be seen in Fig. 1 [13]. Generally speaking, crack originates from the surface of the components or the stress concentration area which includes mechanical gaps. Stress concentration plays a vital role in the process of crack initiation. And in this stage, the crack is inclined and its order is $10^{-4}-10^{-6} \mathrm{~m}$ [14]. After that, the crack will change into microcrack propagation stage. 


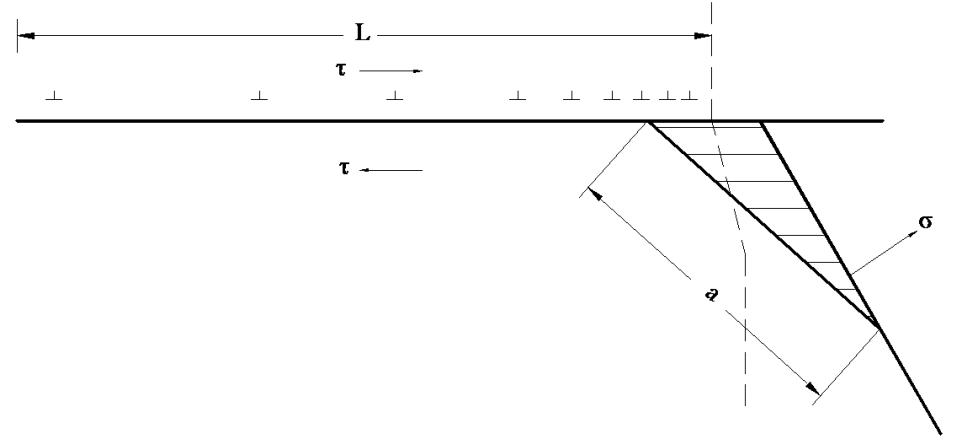

Fig. 1. Model of dislocation pile-up edge [12].

\subsection{Assessment of Crack Initiation Life $\left(N_{i}\right)$.}

1.2.1. Assessment of Crack Initiation Life from the Qualitative Aspect. As it was mentioned above, crack starts from the stress concentration area or the component surface. This is occurs due to presence of many inclusions, mechanical gaps or other defects in the material, which strongly contribute to deterioration of the material fatigue life. The effects of dislocations and debris existing in the material are discussed in a number of publications. A rough scheme for the calculation of stable configuration of super-lattice dislocation dipoles (superdipoles) is depicted in Fig. 2.

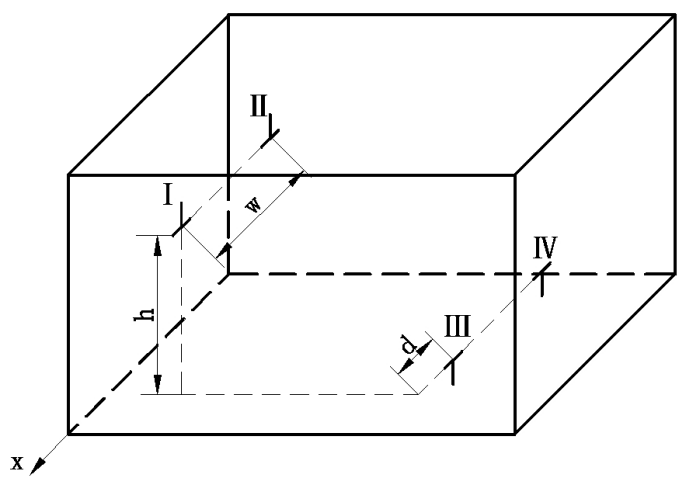

Fig. 2. Schematic representation of superlattice dislocation dipoles and its dimensions in a lattice.

In accordance with the model shown in Fig. 2, the interaction force $f_{x}(x, y)$ for $x$ component can be written as [9]:

$$
f_{x}(x, y)=\frac{\mu b^{2} x\left(x^{2}-y^{2}\right)}{2 \pi(12-v)\left(x^{2}+y^{2}\right)^{2}},
$$

where $\mu$ is the shear modulus, $v$ is Poisson's ratio, and $b$ is magnitude of the Burgers vector $(\widetilde{b})$.

The total interaction forces which are acting at dislocations I and II from the domain antiphase boundary (APB) and three other dislocations are given by [9]:

$$
F_{\mathrm{I}}=-f_{x}(w, 0)+f_{x}(d, h)+f_{x}(d+w, h)+\gamma_{A P B},
$$




$$
F_{\text {II }}=f_{x}(w, 0)+f_{x}(d, h)-f_{x}(w-d, h)-\gamma_{A P B},
$$

where $\gamma_{A P B}$ is the APB energy, $d$ and $w$ are dimensions shown in Fig. 2, which can be derived from formulas (2)-(4) under the premise of $h$ being fixed at some constant value. A new deformation formula can also be derived from Eqs. (2) and (3):

$$
F_{\mathrm{I}}=-\frac{\mu b^{2}}{2 \pi(12-v) w}+\frac{\mu b^{2} d\left(d^{2}-h^{2}\right)}{2 \pi(12-v)\left(d^{2}+h^{2}\right)}+\frac{\mu^{2} b^{2}(d+w)\left[(d+w)^{2}-h^{2}\right]}{2 \pi(12-v)\left[(d+w)^{2}+h^{2}\right]^{2}}+\gamma_{A P B} .
$$

In the last equation, $\mu$ and $v$ are constant values for the certain material, while $w, d$, and $h$ are variables. Thus, the proposed assessment method for $N_{i}$ can be described as follows:

(1) Assume that $w$ and $h$ are invariable. When variable $d$ is increasing, the value of $F_{\text {I }}$ will decrease, in accordance with formula (5).

The increase in $d$ implies a smaller number of dislocations contained in the material, while the decrease in $F_{\mathrm{I}}$ implies that the possibility of dislocation slip will dwindle at the same external condition. The ability to resist deformation can be increased. Therefore, the fewer dislocations are included in the material, the longer is the fatigue life of TiAl alloys.

(2) Assuming that $w$ and $d$ are constant, the same result as shown above can be obtained by rising $h$.

(3) Assuming that $h$ and $d$ are constant, there will be an uncertain result for $F_{\mathrm{I}}$. However, there is no doubt that fewer defects can contribute to its life.

Similarly, another deformation formula can be derived from Eqs. (2) and (4):

$$
F_{\mathrm{II}}=\frac{\mu b^{2}}{2 \pi(12-v) w}+\frac{\mu b^{2} d\left(d^{2}-h^{2}\right)}{2 \pi(12-v)\left(d^{2}+h^{2}\right)^{2}}-\frac{\mu b^{2}(w-d)\left[(w-d)^{2}-h^{2}\right]}{2 \pi(12-v)\left[(w-d)^{2}+h^{2}\right]^{2}}-\gamma_{A P B} .
$$

The analysis of $F_{\text {II }}$ can be conducted similar to the method earlier applied to $F_{\mathrm{I}}$, providing similar trends as those earlier discussed for $F_{\mathrm{I}}$.

The conclusion that fatigue life of TiAl alloys will be improved with fewer defects, to a large extent, can be made from the above analysi. To provide such improvement, trace elements of vanadium and yttrium are added to alloys. Previous works have revealed that the addition of vanadium and yttrium can make grains refined so that mechanical properties and fatigue life (just from the qualitative level) of TiAl alloys will be strongly improved. Trace elements should also be added according toa certain proportion. Only in this way the best performance, meaning fewer defects, can be achieved for TiAl alloys: a higher fatigue life can be attained with fewer defects.

1.2.2. Assessment of Crack Initiation Life from the Quantitative Aspect. The analysis for any problem should include two components: qualitative and quantitative. These two components should be unified and complement each other. The qualitative analysis is the basic premise of quantitative analysis, while the quantitative one will be aimless and useless with no qualitative analysis. Since qualitative analysis will be more scientific and accurate due to quantitative analysis, the latter is also included in this study.

In view of the lack of data for the microstructural dimensions of TiAl alloys, some data on particular alloys are quoted from work [9], since the main goal of this section is to verify the correctness of the qualitative analysis performed in the previous section. Some necessary parameters are tabulated in Table 1 . The parameters $w$ and $d$ are also necessary. However, due to the lack of microstructural dimensions, these two parameters will be referred to as unknowns in the following formulas, in order to make the following analysis universal for various TiAl alloys. Note that although values or $w$ and $d$ are, in the general 
case, unknown, these values are available for certain materials under certain conditions. Authors [9] observed that values of $w$ and $d$ can be derived from Eqs. (3) and (4) if parameter $h$ is fixed at a constant value. However, the values derived from Eqs. (3) and (4) are suitable for the case where each dislocation takes a stable position. For the case of cyclic loading, the values of $w$ and $d$ will vary in accordance with the load, thus the analysis of $F_{\mathrm{I}} / F_{\mathrm{II}}$ ration can be carried out for a varying range of $w$ and $d$.

$\mathrm{T}$ a b 1 e 1

Parameters Used in Calculation (Selected from [9])

\begin{tabular}{||c|c|}
\hline Shear modulus $\mu, \mathrm{GPa}$ & 43.8 \\
\hline Poisson's ratio $v$ & 0.447 \\
\hline Magnitude of the Burgers vector $|\bar{b}|, \mathrm{nm}$ & 0.2888 \\
\hline APB energy $\gamma_{A P B}, \mathrm{~mJ} / \mathrm{m}^{2}$ & 64.6 \\
\hline Height of dipole $h, \mathrm{~nm}$ & 1.0 \\
\hline
\end{tabular}

Using the parameters given in Table 1 and formula (5), the result can be reduced to the following:

$$
\begin{gathered}
F_{\mathrm{I}}=50.326\left[\frac{d\left(d^{2}-1\right)}{\left(d^{2}+1\right)^{2}}-\frac{1}{w}\right](\mathrm{MPa} \sqrt{\mathrm{nm}})+ \\
+2204.288 \frac{(d+w)\left[(d+w)^{2}-1\right]}{\left[(d+w)^{2}+1\right]^{2}}(\mathrm{MPa} \sqrt{\mathrm{nm}})+64.6 \mathrm{~mJ} / \mathrm{m}^{2} .
\end{gathered}
$$

Case 1. The value $w$ is fixed at a constant value and $w>d$ can be obtained from the schematic drawing in Fig. 2. A coefficient $m$ will be adopted to illustrate the relationship between $w$ and $d$. This relationship can be expressed as follows: $w=m d(m>1)$. When $m=2$ is substituted into Eq. (7), the equation can be transformed into the following one:

$$
\begin{gathered}
F_{\mathrm{I}}=25.163 \frac{d^{4}-4 d^{2}-1}{d\left(d^{2}+1\right)^{2}}(\mathrm{MPa} \sqrt{\mathrm{nm}})+6612.864 \frac{d\left(9 d^{2}-1\right)}{\left(9 d^{2}+1\right)^{2}}(\mathrm{MPa} \sqrt{\mathrm{nm}})+ \\
+64.6 \mathrm{~mJ} / \mathrm{m}^{2}=F_{a}(\mathrm{MPa} \sqrt{\mathrm{nm}})+64.6 \mathrm{~mJ} / \mathrm{m}^{2}
\end{gathered}
$$

Thus, when the value of $d$ is increased, $F_{\mathrm{I}}$ is descreased as the result.

Case 2. The value $d$ is fixed at a constant value, and a different deformation equation will be applied for $F_{\mathrm{I}}[d=n w(0<n<1)$, and the value $n=0.5$ is used $]$

$$
\begin{gathered}
F_{\mathrm{I}}=6.29075 \frac{w\left(w^{2}-4\right)}{\left[(1 / 4) w^{2}+1\right]^{2}}(\mathrm{MPa} \sqrt{\mathrm{nm}})+3306.432 \frac{w\left[(9 / 4) w^{2}-1\right]}{\left[(9 / 4) w^{2}+1\right]^{2}}(\mathrm{MPa} \sqrt{\mathrm{nm}})+ \\
+64.6 \mathrm{~mJ} / \mathrm{m}^{2}=F_{b}(\mathrm{MPa} \sqrt{\mathrm{nm}})+64.6 \mathrm{~mJ} / \mathrm{m}^{2}
\end{gathered}
$$

The result is that $F_{\mathrm{I}}$ will decrease with the increase in $w$.

A more accurate result has been obtained from the above analysis. The uncertainty shown in in Section 1.2.1 has been modified. The quantitative analysis of problems can 
contribute to making more extensive and in-depth conclusion in combination with the qualitative analysis.

The relations between $F_{a}$ and $d$, as well as between $F_{b}$ and $w$, are depicted in Fig. 3.

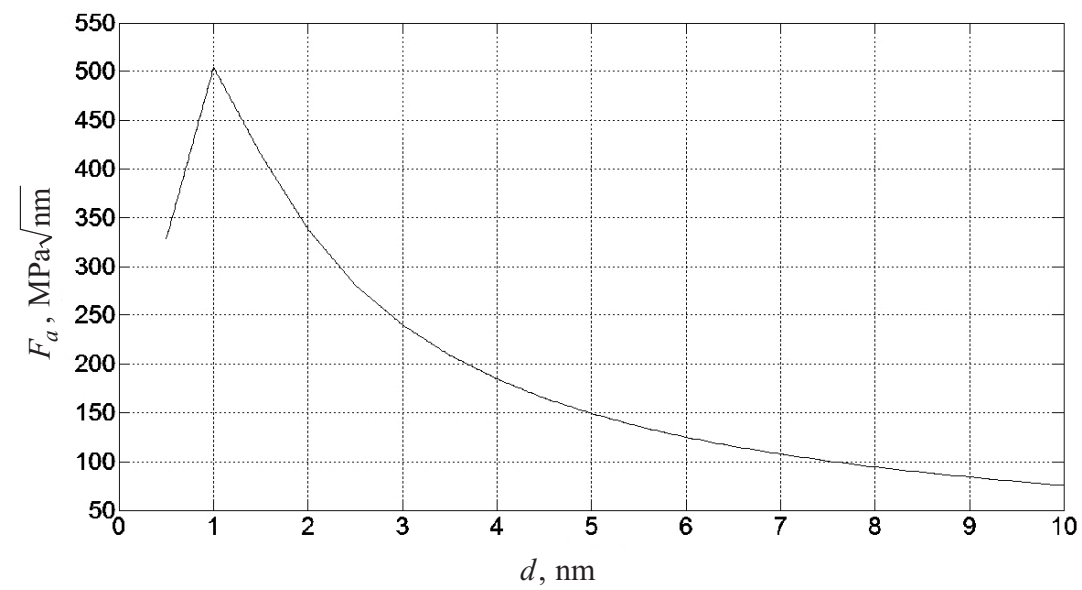

a

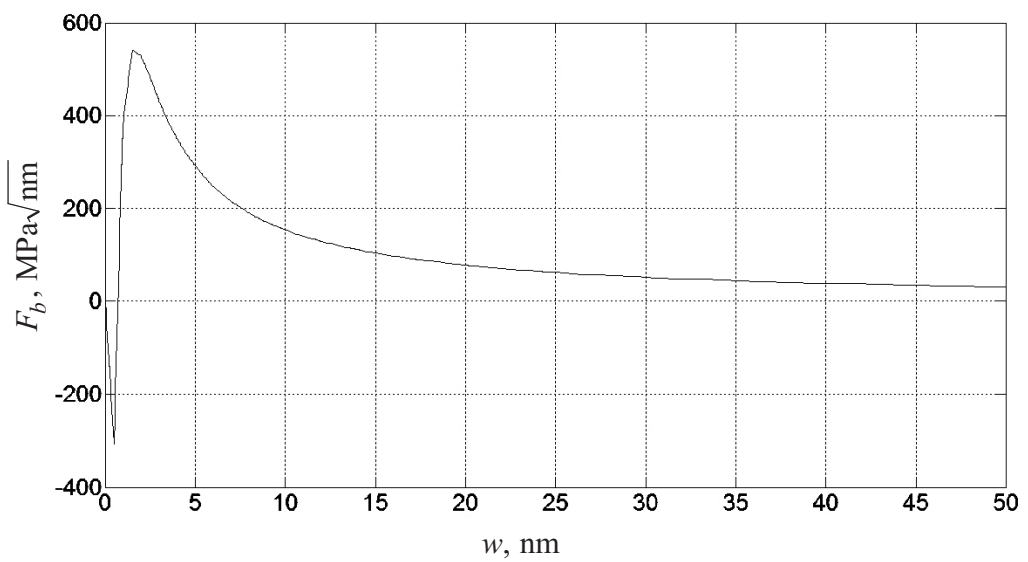

b

Fig. 3. Relation between $F$ and variables $d$ (a) or $w$ (b).

From the above-mentioned relations, the tendency of the curve can be easily traced. In Fig. 3a, $F_{a}$ attains the maximum value when $d$ is in the vicinity of 1 . Then the curve will asymptotically approach zero. The equality $F_{a}=0$ means that the material has no defects, namely, the material is composed of complete grains, and therefore its fracture toughness will be higher and the fatigue life will be longer than those of material with some defects. That is to say, the interaction force of dislocations will be decreased with increasing $d$ (after $F_{a}$ has reached the maximum value). So the conclusion that fatigue life of TiAl alloys can be improved by the addition of trace elements to make grains more refined can be easily made.

In Fig. 3b, $F_{b}$ is maximized when $w$ attains the value of 2.5. Then $F_{b}$ will always fall near zero, and $F_{b}=0$ also means that the material has no defects, namely, the material is an ideal one made up of whole grains. The fatigue life for the ideal material must be longer than that of the material with defects. Thus, trace elements should be added to make 
grains more refined, in order to improve the fatigue life. The fatigue life of TiAl alloys and other materials can usually be improved by making grains more refined with the addition of trace elements.

2. Discussion. It is known that there are many other factors which have strong influence on mechanical properties and fatigue life of materials, in addition to dislocations and debris, as it has been shown above. Examples of these are temperature, loading frequency and stress ratio. However, in this section, the focus is put on the influence of stress ratio. The stress ratio $R=K_{\min } / K_{\max }$ has a significant effect on fatigue life of material, so the discussion of the stress ratio effect is expedient. In double logarithmic coordinates with $d a / d N-\Delta K$, data about $d a / d N-\Delta K$ with banner loading will stratify due to the different values of stress ratio. The influence will be more sensitive for low values of $\Delta K$ [15]. That is to say, the fatigue life of material will be strongly affected by stress ratio. In order to take the stress ratio effect into consideration in the quantitative analysis, a modifying factor $f$ is recommended to be applied in the process of calculation, so that a more accurate result could be reached by modifying the above formula. In this paper, several factors that have an effect on fatigue life have been ignored, so there is a long way to go before an accurate result can be reached.

Conclusions. TiAl alloys play a vital role in modern industies. Dislocations, debris and other defects in TiAl alloys and other materials have a strong effect on the fatigue life. It is important to study new methods for assessing fatigue life, especially for prediction of the fatigue crack initiation life. The following conclusions are made.

1. A new method yielding more accurate results has been obtained via the quantitative rather than qualitative analysis.

2. The fatigue life of TiAl alloys and other materials can be improved by addition of trace alloying elements.

3. The method shown above can also be used for other materials, besides the investigated TiAl alloys.

Acknowledgements. This work was supported by the National Natural Science Fund of China (51065014) and the Program for Changjiang Scholars and Innovative Research Team in University of Ministry of Education of China (IRT1140). R. C. Feng would like to thank Engineering Research Center of Nonferrous Metallurgy's New Equipment, Ministry of Education, Lanzhou University of Technology for providing help.

\section{Резюме}

Запропоновано новий метод оцінки довговічності від утомленості TiAl сплавів за результатами кількісного та якісного аналізу. За допомогою кількісного аналізу визначено вплив мікроструктури TiAl сплавів на їх довговічність від утомленості. Розрахунок зусилля між дислокаціями проведено за стандартною формулою, за допомогою якої можна отримати точний результат. Кількісний та якісний аналіз показав, що довговічність від утомленості можна підвищити шляхом введення мікроелементів, які сприяють подрібненню зерен.

1. T. W. Farthing, "Introducing a new material - the story of titanium," Proc. Inst. Mech. Eng., 191, 59-73 (1977).

2. J. Chen, "High-Nb TiAl alloy with our new lightweight aerospace will enter industrialization," Metal World, 2, 55 (2008).

3. V. Bauer and H.-J. Christ, "Thermomechanical fatigue behavior of a third generation $\gamma$-TiAl intermetallic alloy," Intermetallics, 17, No. 5, 370-377 (2009). 
4. L. Wang, M. Niinomi, S. Takahashi, and M. Hagiwara, "Relationship between fracture toughness and microstructure of Ti-6Al-2Sn-4Zr-2Mo alloy reinforced with TiB particles," Mater. Sci. Eng., A263, 319-325 (1999).

5. S. L. Xiao, L. J. Xu, H. B. Yu, and Y. Y. Chen, "Effect of Y addition on microstructure and mechanical properties of TiAl-based alloys prepared by SPS," Rare Metal Mater. Eng., 42, No. 1, 0023-0027 (2013).

6. L. H. Chai, Y. Y. Chen, and Z. G. Liu, "Effect of Y and Nb on the microstructure and mechanical properties of rapidly solidified TiAl alloys," Rare Metal Mater. Eng., 40, 1976-1981 (2011).

7. Y. Y. Chen, F. T. Kong, J. Tian, et al., "Recent developments in engineering $\gamma$-TiAl intermetallics," Trans. Nonferrous Met. Soc. China, 12, No. 4, 605-609 (2002).

8. Y. Li, D. N. Crowther, M. J. W. Green, et al., "The effect of vanadium and niobium on the properties and microstructure of the intercritically reheated coarse grained heat affected zone in low carbon microalloyed steels," ISIJ Int., 41, No. 1, 46-55 (2001).

9. Y. Koizumi, T. Nakano, and Y. Umakoshi, "Dislocation dipoles in cyclically deformed $\mathrm{Ti}_{3} \mathrm{Al}$ single crystals," Intermetallics, 8, 179-186 (2000).

10. J. M. Larsen, S. K. Jha, C. J. Szczepanski, et al., "Reducing uncertainty in fatigue life limits of turbine engine alloys," Int. J. Fatigue, 57, 103-112 (2013).

11. X. J. Wu, Evolution of Life in Metallic Materials, University of Science and Technology of China, Anhui (2009).

12. Y. X. Cui and C. L. Wang, Analysis of Metal Fracture Surface, Harbin Institute of Technology, Heilongjiang (1998).

13. T. Y. Fan, Basic Theory of Fracture, Science Press, Beijing (2003).

14. Y. S. Feng, Analysis and Advanced Design Principle of Aircraft Structure, Northwestern Polytechnical University, Shaanxi (1991).

15. X. L. Liu, Z. Zhang, and C. H. Tao, Fatigue Fractography Quantitative Analysis, National Defense Industry Press, Beijing (2010). 